\title{
Impact of the COVID-19 Pandemic on Radiology in Inpatient and Outpatient Care in Germany: A Nationwide Survey Regarding the First and Second Wave
}

\section{Auswirkungen der COVID-19-Pandemie auf die radiologische Versorgung im stationären und ambulanten Bereich in Deutschland: Eine bundesweite Umfrage bezüglich der ersten und zweiten Welle}

Authors

Simon Bernatz ${ }^{10}$, Saif Afat $^{2}$, Ahmed E. Othman², Konstantin Nikolaou², Malte Sieren ${ }^{3}$, Marwin-Jonathan Sähn ${ }^{4}$, Daniel Pinto dos Santos ${ }^{5}$, Tobias Penzkofer ${ }^{6}$, Andreas Michael Bucher ${ }^{1}$, Bernd Hamm ${ }^{6}$, Thomas J. Vogl ${ }^{1}$, Boris Bodelle RACOON Consortium

Alexander Gussew, Alexander König, Alexey Surov, Andreas Bucher, Andreas Mahnken, Arno Bücker, Bernd Hamm, Birte Valentin, Christian Stroszczynski, Christiane Kuhl, Christoph Düber, Christopher Kloth, Daniel Kütting, David Maintz, Elmar Kotter, Evelyn Bohrer, Fabian Bamberg, Felix Güttler, Felix Meinel, Florian Schwarz, Frank Wacker, Frederik Kostka, Gabriele Krombach, Gerald Antoch, Gerhard Adam, Gudrun Borte, Hans-Ulrich Kauczor, Hinrich Winther, Jens Kleesiek, Jens Ricke, Jens-Peter Kühn, Joachim Lotz, Jörg Barkhausen, Kersten Peldschus, Konstantin Nikolaou, Maciej Pech, Malte Sieren, Marc-André Weber, Marcus Both, Marcus Makowski, Matthias Fink, Matthias Frölich, Matthias May, Meinrad Beer, Michael Forsting, Michael Ingrisch, Michael Uder, Norbert Hosten, Okka Hamer, Olav Jansen, Peter Isfort, Philipp Josef Kuhl, Ralf-Thorsten Hoffmann, Rickmer Braren, Robert Rischen, Roman Klöckner, Saheeb Ahmed, Saif Afat, Simon Pätzholz, Stefan Schönberg, Thomas Kröncke, Thomas Vogl, Thorsten Bley, Thorsten Persigehl, Timm Denecke, Tobias Penzkofer, Ulf Teichgräber, Ulrike Attenberger, Volkmar Nicolas, Walter Heindel, Walter Wohlgemuth

Affiliations

1 Department of Diagnostic and Interventional Radiology, Goethe University Frankfurt, Frankfurt am Main, Germany

2 Department of Radiology, University Hospitals Tübingen, Germany

3 Department of Radiology and Nuclear Medicine, University Hospital Schleswig-Holstein Campus Lübeck, Lübeck, Germany

4 Interventional and Diagnostic Radiology, University Hospital Aachen, Germany

5 Department of Radiology, University Hospital Cologne, Germany

6 Department of Radiology, Charité Medical Faculty Berlin, Germany

Key words COVID-19, SARS-CoV-2, outpatients, inpatients, surveys and questionnaires

received 19.05.2021

accepted 13.07.2021

published online 14.10.2021
Bibliography

Fortschr Röntgenstr 2022; 194: 70-82

DOI 10.1055/a-1586-3278

ISSN 1438-9029

(C) 2021. Thieme. All rights reserved.

Georg Thieme Verlag KG, Rüdigerstraße 14,

70469 Stuttgart, Germany

Correspondence

Dr. Saif Afat

Diagnostische und Interventionelle Radiologie,

Universitätsklinikum Tübingen, Hoppe-Seyler-Straße 3,

72076 Tübingen, Germany

Tel.: +49/70 71/2968423

saif.afat@med.uni-tuebingen.de

Supplementary material is available under

https://doi.org/10.1055/a-1586-3278

\section{ZUSAMMENFASSUNG}

Zielsetzung Das Ziel war, die Meinungen des stationären und ambulanten medizinisch-radiologischen Personals zu den Maßnahmen zu ermitteln, die im Zusammenhang mit der COVID-19-Pandemie während der ersten und zweiten Welle ergriffen wurden. Zusätzlich sollten die Maßnahmen identifiziert werden, die noch als verbesserungsbedürftig angesehen werden. 
Materialien und Methoden Wir führten eine anonyme, onlinebasierte Umfrage unter mehr als 10000 Radiolog/innen und medizinisch-technischen Radiologieassistent/innen (MTRA) in Deutschland vom 5.-31. Januar 2021 durch. Insgesamt erhielten wir 862 Antworten (Chefärzt/innen $n=225$ (stationär tätige Ärzt/innen $n=138$, ambulant tätige Ärzt/innen $n=84, N / A n=3$ ); radiologisches Personal $n=637$ (stationär tätige Ärzt/innen $n=303$, ambulant tätige Ärzt/innen $n=50$, stationär tätige MTRA $n=217$, ambulant tätige MTRA $n=26, N / A n=41)$ ). Es wurden Schätzfragen, Ja/Nein-Fragen und Likert-ähnliche Skalen verwendet.

Ergebnisse Während der ersten/zweiten Welle stimmten $70 \%$ (86/123)/43\% (45/104) der stationären und 26\% (17/ 66)/10\% (5/52) der ambulanten Chefärzt/innen zu, finanzielle Unterstützung von den Behörden erhalten zu haben, aber die Mehrheit bewertete die finanzielle Unterstützung als nicht ausreichend. Während der ersten und zweiten Welle stimmten $33 \%$ (8/24) und $80 \%$ (16/20) der ambulanten MTRA zu, dass sie ausreichend mit persönlicher Schutzausrüstung ausgestattet wurden. Der wahrgenommene Mangel an persönlicher Schutzausrüstung verbesserte sich bei allen Teilnehmern während der zweiten Welle. Stationäre/ambulante MTRA empfanden in der ersten und zweiten Welle eine erhöhte Arbeitsbelastung: $72 \%$ (142/198)/79\% (19/24) und $84 \%(146 / 174) / 80 \%(16 / 20)$.

Zusammenfassung MTRA scheinen von der COVID-19-Pandemie in Deutschland zunehmend negativ betroffen zu sein. Die finanzielle Unterstützung durch die zuständigen Behörden scheint verbesserungsbedürftig zu sein.

\section{Kernaussagen:}

- Die Verfügbarkeit von persönlicher Schutzausrüstung hat sich in der zweiten Welle verbessert.

- Insbesondere MTAs scheinen zunehmend negativ von der COVID-19-Pandemie betroffen zu sein.

- Die finanzielle und beratende Unterstützung durch die Regierung könnte verbessert werden.

\section{ABSTRACT}

Objectives To find out the opinion of radiological inpatient and outpatient medical staff regarding the measures taken in relation to the COVID-19 pandemic during the first and second waves and to identify the measures that are still perceived as needing improvement.

Materials and Methods We conducted an anonymous online survey among more than 10000 radiologists/technicians in Germany from January 5 to January 31, 2021. A total of 862 responses (head physicians, $n=225$ [inpatient doctors, $\mathrm{n}=138$; outpatient doctors, $\mathrm{n}=84 ; \mathrm{N} / \mathrm{A}, \mathrm{n}=3$ ]; radiologic personnel, $n=637$ [inpatient doctor, $n=303$; outpatient doctor, $\mathrm{n}=50$; inpatient technician, $\mathrm{n}=217$; outpatient technician, $n=26$; N/A, $n=41]$ ) were received. Questions of approximation, yes/no questions, and Likert scales were used.

Results During the first/second wave, $70 \%(86 / 123) / 43 \%$ (45/104) of inpatient and $26 \%(17 / 66) / 10 \%$ (5/52) of outpatient head physicians agreed that they received financial support from the authorities but the majority rated the financial support as insufficient. During the first and second wave, $33 \%(8 / 24)$ and $80 \%(16 / 20)$ of outpatient technicians agreed that they were adequately provided with personal protective equipment. The perceived lack of personal protective equipment improved for all participants during the second wave. Inpatient [outpatient] technicians perceived an increased workload in the first and second wave: $72 \%(142 / 198)[79 \%$ (19/24)] and $84 \%(146 / 174)$ [80\% (16/20)]. Conclusion: Technicians seem increasingly negatively affected by the COVID-19 pandemic in Germany. Financial support by the competent authorities seems to be in need of improvement.

\section{Key Points:}

- The accessibility of personal protective equipment resources improved in the second wave.

- In particular, radiology technicians seem increasingly negatively affected by the COVID-19 pandemic.

- Financial and consulting support from the government could be improved.

\section{Citation Format}

- Bernatz S, Afat S, Othman AE et al. Impact of the COVID-19 Pandemic on Radiology in Inpatient and Outpatient Care in Germany: A Nationwide Survey Regarding the First and Second Wave. Fortschr Röntgenstr 2022; 194: 70-82

\section{Introduction}

The World Health Organization (WHO) declared the Coronavirus disease 2019 (COVID-19) a Public Health Emergency of International Concern in January 2020 [1]. In late June, approximately 3.7 million cases (3734 830 cases; 6/29/2021) and more than 90.8 deaths (90 828 deaths; 6/29/2021) were counted in Germany [2, 3]. Radiology departments are instrumental in patient management and in supporting COVID-19 diagnosis [4]. Real-time polymerase chain reaction (RT-PCR) remains the standard of reference for COVID-19 detection, but false-negative tests can occur, emphasizing the importance of radiological assessment and reporting [4-6]. Though up to approximately $50 \%$ of early
CT scans can be normal, the often typical morphologic changes promote the importance of radiologic imaging for patient management $[4,7,8]$. Healthcare professionals may deal with a higher infection risk due to aerosols as a result of close patient contact and invasive patient care. In radiology, especially interventional radiologists and technicians are at increased risk [9, 10]. Lack of training, experience or risk management plans may increase fear and a poor emotional state for an individual [10]. Moreover, the pandemic impacts healthcare on an institutional level with potential depletion of personal protective equipment resources and financial difficulties [11]. Radiology departments may have to dynamically restructure their workflows and educational and financial strategies to deal with rapidly changing information re- 


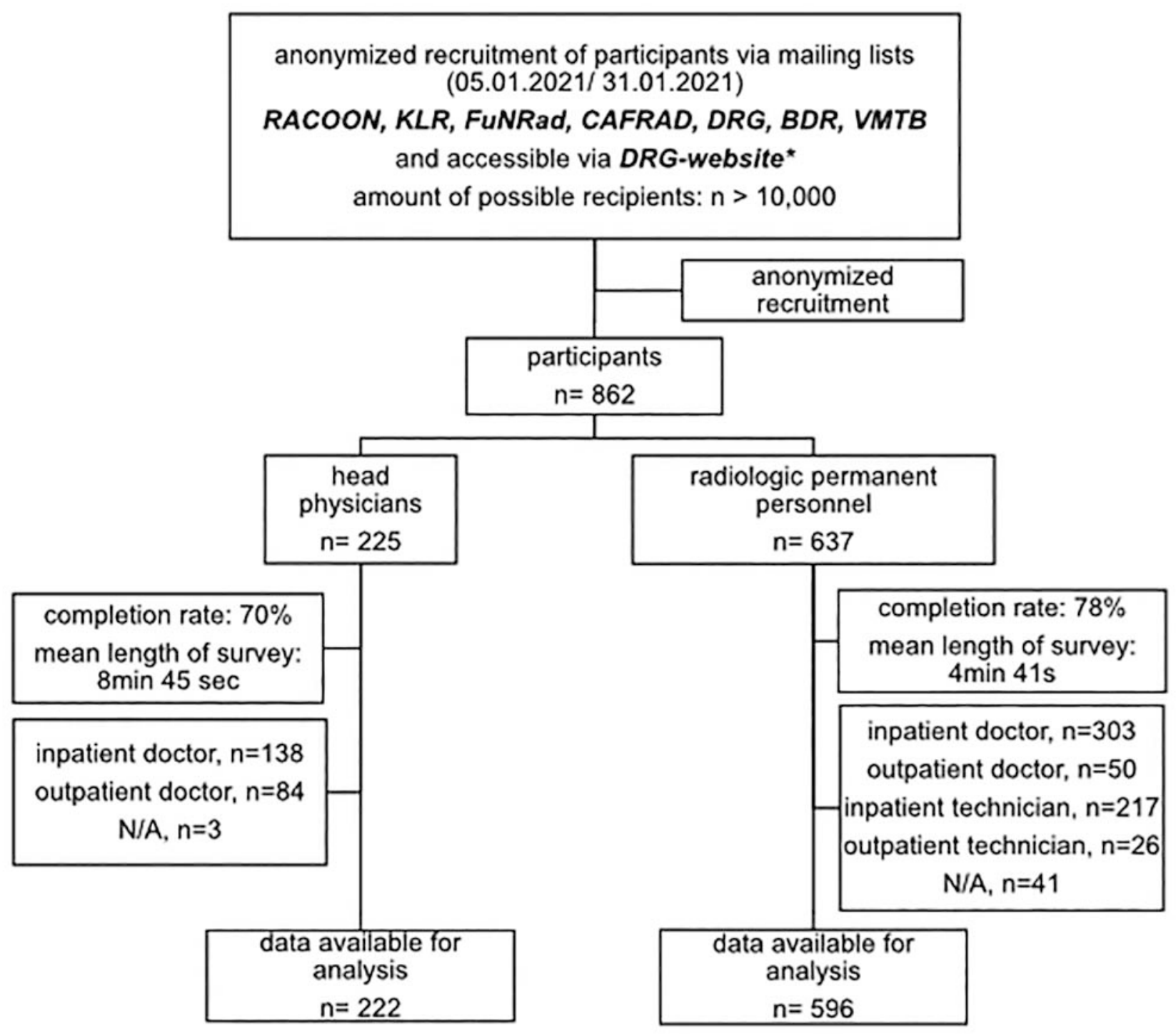

- Fig. 1 Flowchart of participant recruitment into the study. In total, 862 participants took part in the survey. A completion rate of $70 \%$ among head physicians and $78 \%$ among resident/senior physicians and technicians was achieved. We distributed the survey via online mailing lists as well as on the website of the DRG ( ${ }^{*}$ https://www.drg.de/de-DE/7606/helfen-sie-mit-die-effekte-der-covid-19-pandemie-in-der-radiologie-besser-zuverstehen/). BDR: Berufsverband der Deutschen Radiologen e. V.; CAFRAD: Chefarztforum Radiologie of the DRG; DRG: Deutsche Röntgengesellschaft; FuNRad: Forum niedergelassener Radiologen of the DRG; KLR: Konferenz der Lehrstuhlinhaber für Radiologie E. V.; VMTB: Vereinigung Medizinisch-Technischer Berufe. RACOON: radiological cooperative network of the COVID-19 pandemic.

- Abb. 1 Flussdiagramm der Teilnehmerrekrutierung in die Studie. Insgesamt haben 862 Teilnehmer an der Umfrage partizipiert. Es wurde eine Abschlussrate von 70 \% bei Chefärzt/innen und 78 \% bei Assistenz-/Oberärzt/innen und MTRA erreicht. Wir haben die Umfrage über Online-Mailinglisten geteilt sowie über die Website der DRG veröffentlicht $\left({ }^{*}\right.$ https://www.drg.de/de-DE/7606/helfen-sie-mit-die-effekte-der-covid-19-pandemie-in-derradiologie-besser-zu-verstehen/). BDR = Berufsverband der Deutschen Radiologen e. V.; CAFRAD = Chefarztforum Radiologie; DRG = Deutsche Röntgengesellschaft; FuNRad = Forum niedergelassener Radiologen; KLAR = Konferenz der Lehrstuhlinhaber für Radiologie e. V.; VMTB =Vereinigung Medizinisch-Technischer Berufe; RACOON = radiological cooperative network of the COVID-19 pandemic.

garding the disease [11-15]. Alhasan et al. reported the perceived negative impact of the pandemic on radiologic clinical activity in Saudi Arabia [16]. In Germany, we have quite successfully coped with three waves up to now and we have administered more than 72000000 vaccine doses (72153878 vaccine doses administered; 6/29/2021) [2, 3]. The creation of crisis leadership teams with enterprise-wide communication has been proposed to determine the need for course corrections on a dynamic basis [11].

Our aim was to analyze changes in radiological health workers' opinions regarding the measures taken from the first to the second wave. This is to identify possible strengths and weaknesses of current developments in crisis management and to identify measures 
that appear to be in need of improvement. To assess and compare these challenges in the inpatient and outpatient sectors during the first and second wave of the COVID-19 pandemic, we conducted a nationwide survey of hospitals of various size and radiology practices. The goal was to obtain the opinions of a broad range of participants, including physicians and technicians.

\section{Materials and Methods}

The population was not reported previously. This anonymous survey was exempt from approval by the institutional review board.

\section{Study design}

In this nationwide prospective study, an online completely anonymous voluntary survey was conducted via multiple email distribution lists and an online website (German Roentgen Society, DRG) within the network of University Medicine (NUM) and the Radiological Cooperative Network of the COVID-19 pandemic (RACOON) from January 5 to January 31,2021 . We reached out to more than 10000 people working in the radiologic inpatient (hospitals) and outpatient (private practices) sector as we depict in detail in $\mathbf{~ F i g . ~} \mathbf{1}$.

\section{Survey}

We collected the survey data employing SurveyMonkey (SurveyMonkey Europe UC). We conducted a comprehensive survey including 62 questions for head physicians (Supplementary Fig. 1) and a condensed format of 33 questions for all other participants (Supplementary Fig.2). The decision to divide the questionnaire into a reduced and a comprehensive questionnaire was made considering that certain questions, such as the financial support of the department or the staffing ratio expected in the future, would be answered adequately mainly by the head physicians. In addition, the condensed questionnaire should increase the response rate of the other participants. The survey was structured to obtain general data, specific data for the first wave (01/20-06/20) and the second wave (since 06/20) as well as perspectives. The questions regarding the first and second wave were included in one questionnaire at one time point and were structured in 4 categories (level of information, communication, work safety, direct consequences) and were asked at first for the first wave and afterwards (in the second part of the same questionnaire) for the second wave. This study design should promote higher response rates for both waves and increase the independence of respondents' ratings. We employed a 4-point Likert scale, closed (yes/no), single- and multiple-choice questions, and approximation questions. The questionnaire was developed by the first and senior authors (SB, BB) and revised and approved by the external coauthors and respective members of the RACOONnetwork.

The comprehensive [condensed] survey consisted of the following questions. General questions ( $n=7$ [5]) were asked to epidemiologically structure the data and enable subgroup analyses. The following questions were first asked concerning the first wave and asked again in the second part of the questionnaire concerning the second wave. The level of information section $(n=8$ [8]) asked questions to tackle the accessibility and transparency with respect to COVID-19-infected patient management and sanitation guidelines. In the communications ( $n=5$ [1]) section, respondents rated the influence of the government and health authorities. Work safety ( $n=4$ [3]) was rated for radiologists and technicians. In the direct consequences section ( $n=9$ [2]) participants elucidated the direct impact on their workflow, patient management and the institution. The perspectives section $(n=3$ [0]) focused on institutional economic aspects and these questions were only asked one time for the head physicians.

\section{Statistical analysis}

We conducted statistical analyses in JMP 14 (SAS Institute) and in R [17] (version 4.0.2; R Foundation for Statistical Computing) with RStudio [18] (version 1.4.1103; RStudio) applying the R package Likert (version1.3.5; https://www.rdocumentation.org/packages/ likert/versions/1.3.5). For the analyses, we summarized the Likert scale response options as follows: fully/rather agree as agree; fully/ rather disagree as disagree. For subgroup analysis of participants according to their working position, we excluded respondents who defined their working position as "other" or who did not specify ( $\mathrm{N} /$ A) their working position $(n=44)$. In 2019, 8571 radiologists worked in outpatient $(n=4176)$ and inpatient $(n=4395)$ care in Germany [19]. Consequently, we calculated a sample size of 368 radiologists to reach a margin of error of $\pm 5 \%$ within a $95 \%$ confidence interval. In 2018, 26641 radiology technicians worked in Germany [20]. Consequently, we calculated a sample size of 195 technicians to reach a margin of error of $\pm 7 \%$ within a $95 \%$ confidence interval. Graphical illustrations were performed employing Affinity Designer 1.8.5.703 (Serif (Europe) Ltd).

\section{Results}

\section{Study population}

In total, 225 heads of department (62\% (138/222), inpatient doctors (ID); $38 \%$ (84/222) outpatient doctors (OD); $n=3, N / A)$ and 637 radiologic personnel (51\% (303/596), ID; $8 \%$ (50/596), OD; $36 \%$ (217/596), inpatient technicians (IT); $4 \%$ (26/596), outpatient technicians (OT); $n=41, N / A)$ took part in the survey. 32 head physicians, 145 ID, and 87 IT worked at university hospitals. Most participants used the public general news as the primary source of information $(74 \%, 602 / 817)$ followed by e-mails from management. In inpatient care (IC) and outpatient care (OC), $95 \%(624 / 657)$ and $66 \%$ (105/106) of respondents stated that they had been treating COVID-19-positive patients since the first wave. Respondents stated that $1 \%$ (5/657) of IC and $19 \%(31 / 160)$ of OC facilities had never treated COVID-19-positive patients. See Supplementary Fig. 3 for detailed epidemiologic data of the study population.

\section{Level of information and sanitation protocols}

During the first wave, $88 \%$ (350/399)/44\% (51/116) of IDs/ODs and $84 \%(174 / 207) / 33 \%(8 / 24)$ of ITs/OTs agreed that an email feed was introduced. In the second wave the level of agreement was rather constant in IC and improved in OC to $49 \%$ (45/92)/45\% (10/22) for ODs/OTs. During the first wave, $80 \%(317 / 398) / 48 \%$ 


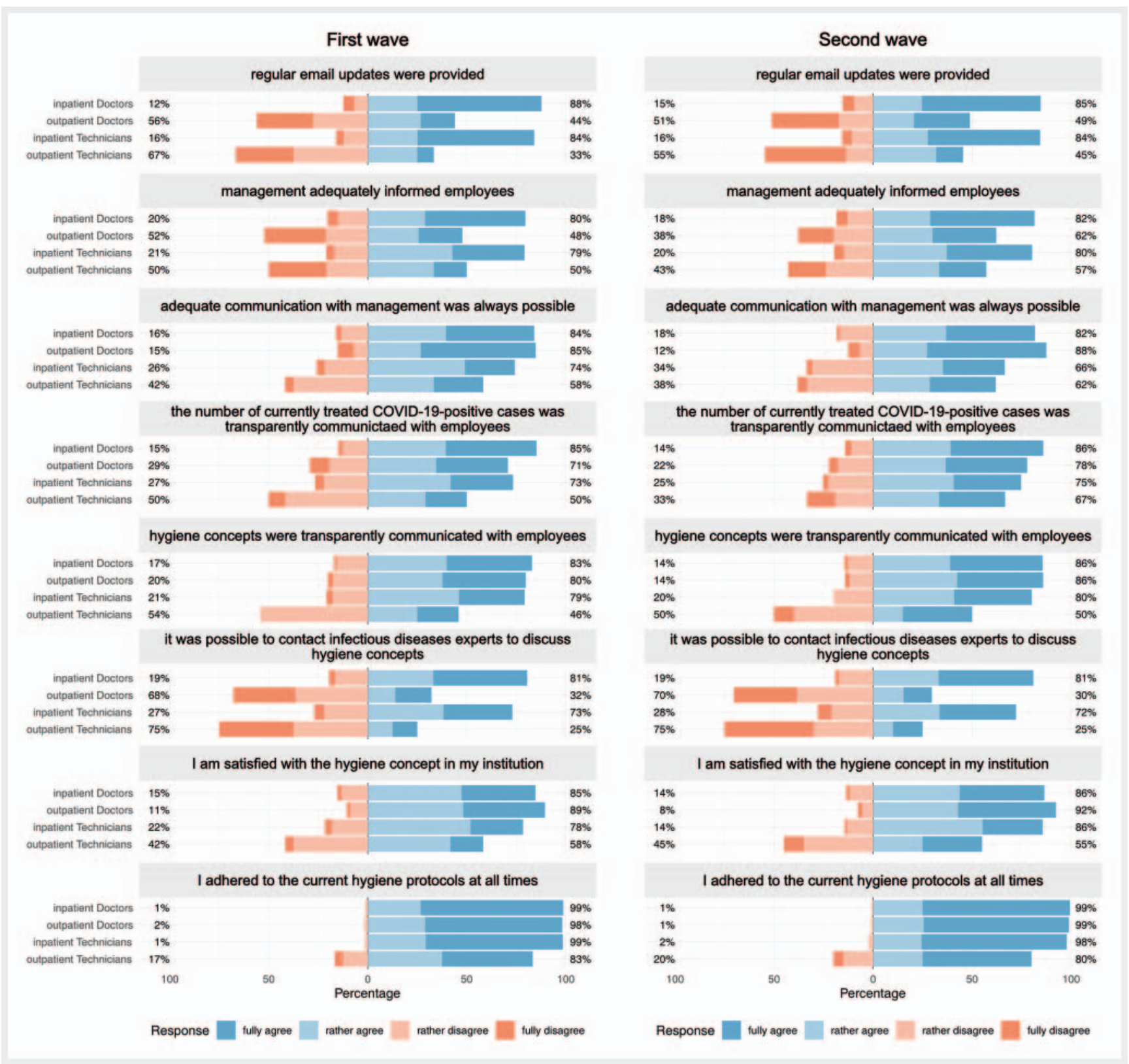

- Fig. 2 Responses to the information section: first vs. second wave. Total answers for each question, counted from the top: \#1 wave: 746,741 , 733, 739, 739, 738, 741, 740; \#2 wave: 656, 651, 638, 648, 648, 638, 647, 646.

- Abb. 2 Antworten für den Abschnitt „Information“: erste vs. zweite Welle. Gesamtantworten für jede Frage, von oben gezählt: \#1 Welle: 746, 741, 733, 739, 739, 738, 741, 740; \#2 Welle: 656, 651, 638, 648, 648, 638, 647, 646.

(54/113) of IDs/ODs and 79\% (163/206)/50\% (12/24) of ITs/OTs agreed that management adequately informed employees. In the second wave the level of agreement improved in OC to $62 \%$ $(56 / 90) / 57 \%$ (12/21) for ODs/OTs. During both waves at least $85 \%$ (340/399) of IDs agreed that the number of currently treated COVID-19-positive patients was transparently communicated. The level of agreement was at least $71 \%(80 / 113)$ among ODs and ITs. The level of agreement was $50 \%(12 / 24)$ and $67 \%(14 / 21)$ for OTs in the first and second wave. During both waves, at least $79 \%$ (160/202) of IDs, ODs, or ITs agreed that the hygiene concepts were transparently communicated with the employees with improvement in the second wave. The level of agreement was $46 \%(11 / 24)$ and $50 \%(10 / 20)$ for OTs in the first and second wave. During the first wave, $81 \%$ (318/395)/32\% (37/115) of IDs/ODs and $73 \%$ (149/204)/25\% (6/24) of ITs/OTs agreed that it was possible to contact an infectious disease expert to discuss hygiene concepts. The level of agreement remained rather constant during the second wave. At least $85 \%$ (338/399) of IDs and ODs agreed that they were satisfied with the hygiene concept of their institution during the first wave, with improvement in the second wave to up to $92 \%$ 


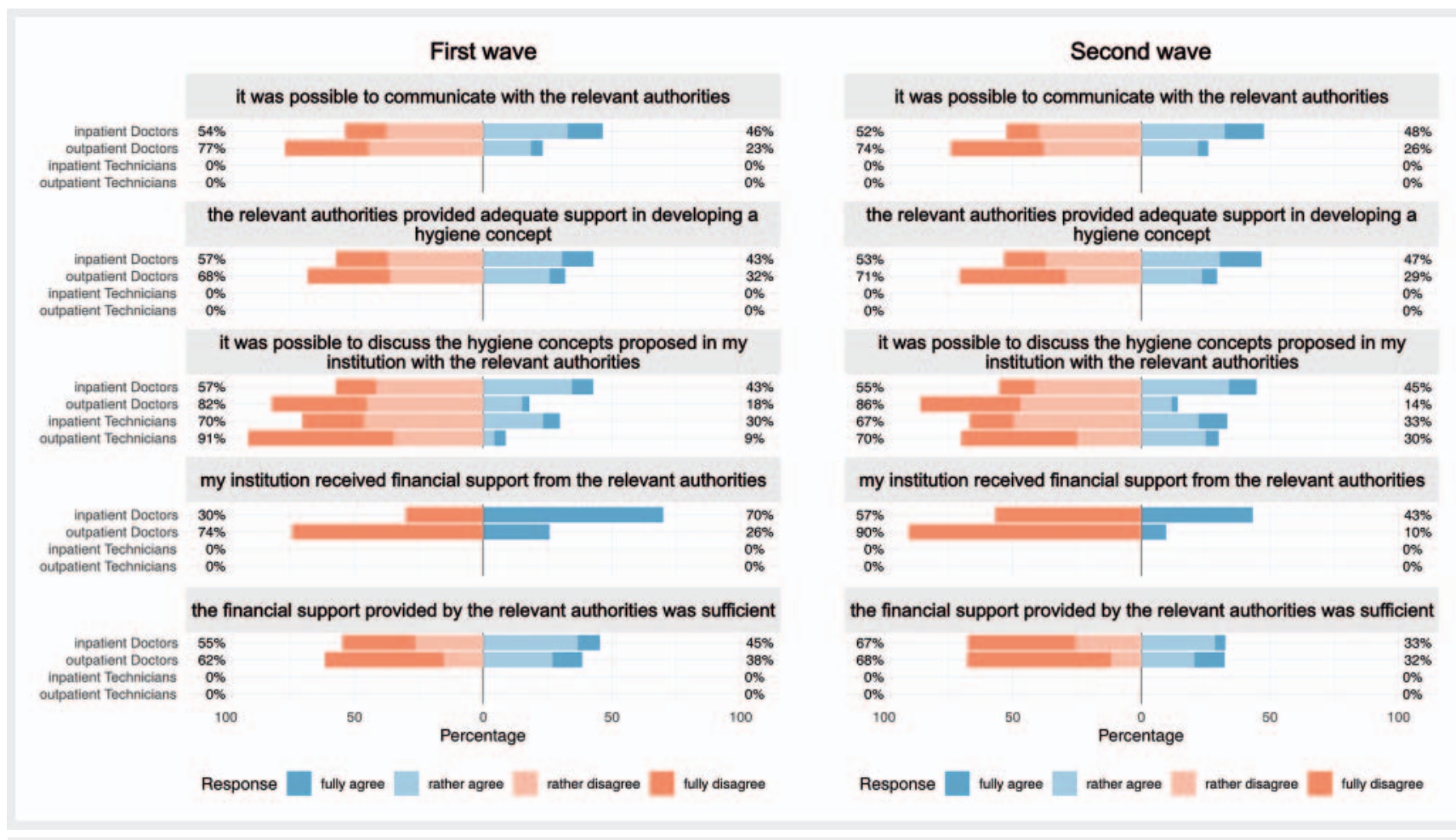

- Fig. 3 Responses to the government and authorities section: first vs. second wave. Total answers for each question, counted from the top: \#1 wave: 190, 190, 660, 189, 169; \#2 wave: 155, 156, 584, 156, 132. Questions 1, 2, 4, 5 were only part of the dedicated survey for head physicians.

- Abb. 3 Antworten zum Abschnitt „Regierung und Behörden“: erste vs. zweite Welle. Gesamtantworten für jede Frage, von oben gezählt: \#1 Welle: 190, 190, 660, 189, 169; \#2 Welle: 155, 156, 584, 156, 132. Die Fragen 1, 2, 4 und 5 waren nur Teil der spezifischen Umfrage für Chefärzt/ innen.

(84/91, OD). The level of agreement was $78 \%(160 / 204) / 58 \%$ $(14 / 24)$ for ITs/OTs in the first and $86 \%(155 / 181) / 55 \%(11 / 20)$ for ITs/OTs in the second wave. During both waves, at least $98 \%$ (202/205) of IDs/ODs/ITs agreed that they adhered to the hygiene protocols at all times. The level of agreement of OTs was $83 \%$ (20/ 24) and $80 \%(16 / 20)$ during the first and second wave. See $>$ Fig. 2.

\section{Communication with the government and authorities}

During both waves less than $50 \%$ (maximum $48 \%$ (50/105), ID, second wave) of IDs agreed that it was possible to communicate with relevant authorities and that the relevant authorities provided adequate support in developing a hygiene concept. During both waves the agreement rates were less than $32 \%$ (maximum $32 \%$ $(21 / 66)$, OD, first wave) among ODs. During both waves, under $45 \%$ (146/326)/18\% (19/106) of IDs/ODs agreed that it was possible to discuss the hygiene concepts proposed in their institution with the relevant authorities. The level of agreement was as low as $30 \%$ (50/168, first wave) among ITs and $9 \%$ (2/23, first wave) among OTs. During the first wave, more IDs $(70 \%(86 / 123))$ than ODs $(26 \%(17 / 66))$ agreed that they received financial support from the relevant authorities. The level of agreement was reduced during the second wave. During the first wave $45 \%$ (53/117)/38\% (20/52) of IDs/ODs agreed that the financial support provided by the relevant authorities was sufficient. The level of agreement was reduced during the second wave. See $>$ Fig. 3 .

\section{Work safety}

From the first to the second wave, more radiologists and technicians agreed that adequate personal protective equipment was provided. Exemplarily, in the first and second wave $33 \%$ (8/24) and $80 \%(16 / 20)$ of OTs agreed that they were adequately provided with personal protective equipment ( $\triangleright$ Fig. 4 A). In OC, the perceived lack of personal protective equipment was higher than in IC. Technicians perceived a higher lack compared to doctors. The most pronounced lack of personal protective equipment was perceived with regard to disinfectants with $73 \%$ (19/26) among OTs in the first wave and $31 \%(8 / 26)$ in the second wave. For all personal protective equipment, the perceived lack was reduced in the second wave ( $\triangleright$ Fig. 4B).

\section{Direct consequences}

During the first and second wave, $16 \%(18 / 111, \mathrm{ID}), 3 \%(1 / 36$, OD) and $12 \%(13 / 104$, ID), $3 \%(1 / 37$, OD) had to be relocated to direct patient care. During the first and second wave, 37\% (41/ 111, ID), $22 \%$ (12/54, OD) and $17 \%(18 / 105$, ID), $10 \%(4 / 40$, OD) of scanners were assigned to COVID-19-positive patients exclusively. Up to $51 \%$ (176/343, ID, second wave) of doctors and up to $84 \%$ (146/174, IT, second wave) of technicians agreed that they had an increased workload with a higher level of agreement in the second wave. In the second wave, fewer participants agreed that short-time work or reduction of accumulated over- 


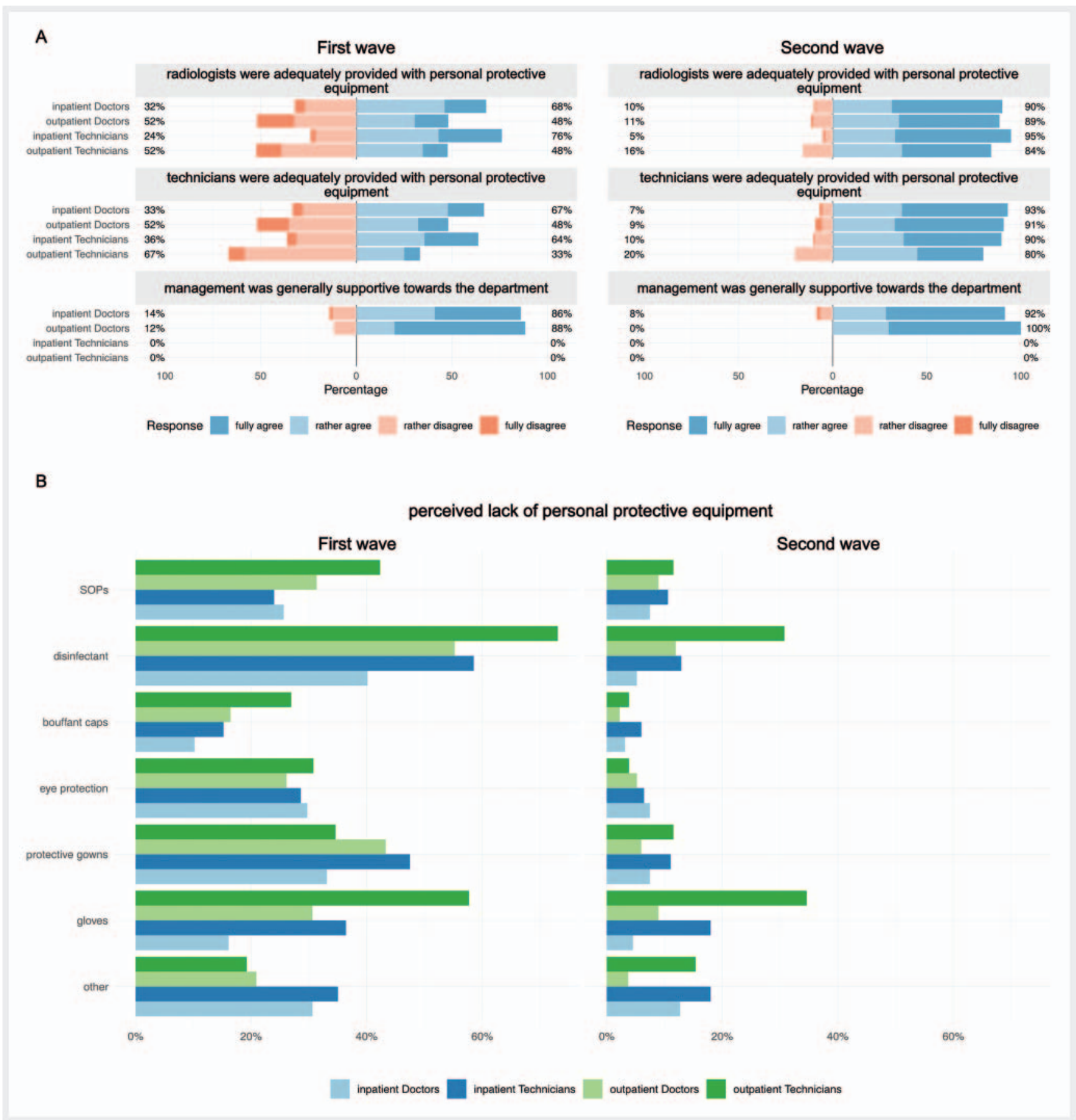

- Fig. 4 Responses to the work safety and protective measures section: first vs. second wave. A Total answers for each question, counted from the top: \#1 wave: 701, 707, 182; \#2 wave: 623, 628, 153. Question 3 was only part of the dedicated survey for head physicians. B Missing answers: \#1 wave: 58; \#2 wave: 145.

- Abb.4 Antworten zum Abschnitt „Arbeitssicherheit und Schutzmaßnahmen“: erste vs. zweite Welle. A Gesamtantworten für jede Frage, von oben gezählt: \#1 Welle: 701, 707, 182; \#2 Welle: 623, 628, 153. Frage 3 war nur Teil der spezifischen Umfrage für Chefärzt/innen. B Fehlende Antworten: \#1 Welle: 58; \#2 Welle: 145.

time hours was enforced ( $\bullet$ Fig. 5). In IC and OC most scanners were significantly less shut down in the second wave ( $\vee$ Table 1 ). Examinations were reduced up to 31 \% (Cl 23.9-38.9, OD, CT examinations) ( $\triangleright$ Table 2 ) and delayed emergency examinations were reported in up to $4.6 \%(\mathrm{Cl} 1.8-7.3)$ exemplarily in the first wave for IC angiography ( $\triangleright$ Table 3 ). For most scanners, there were significantly fewer decreases in examinations in the second wave. Details regarding infections and quarantine measures of IC/OC doctors and technicians are depicted in > Table 4 . 


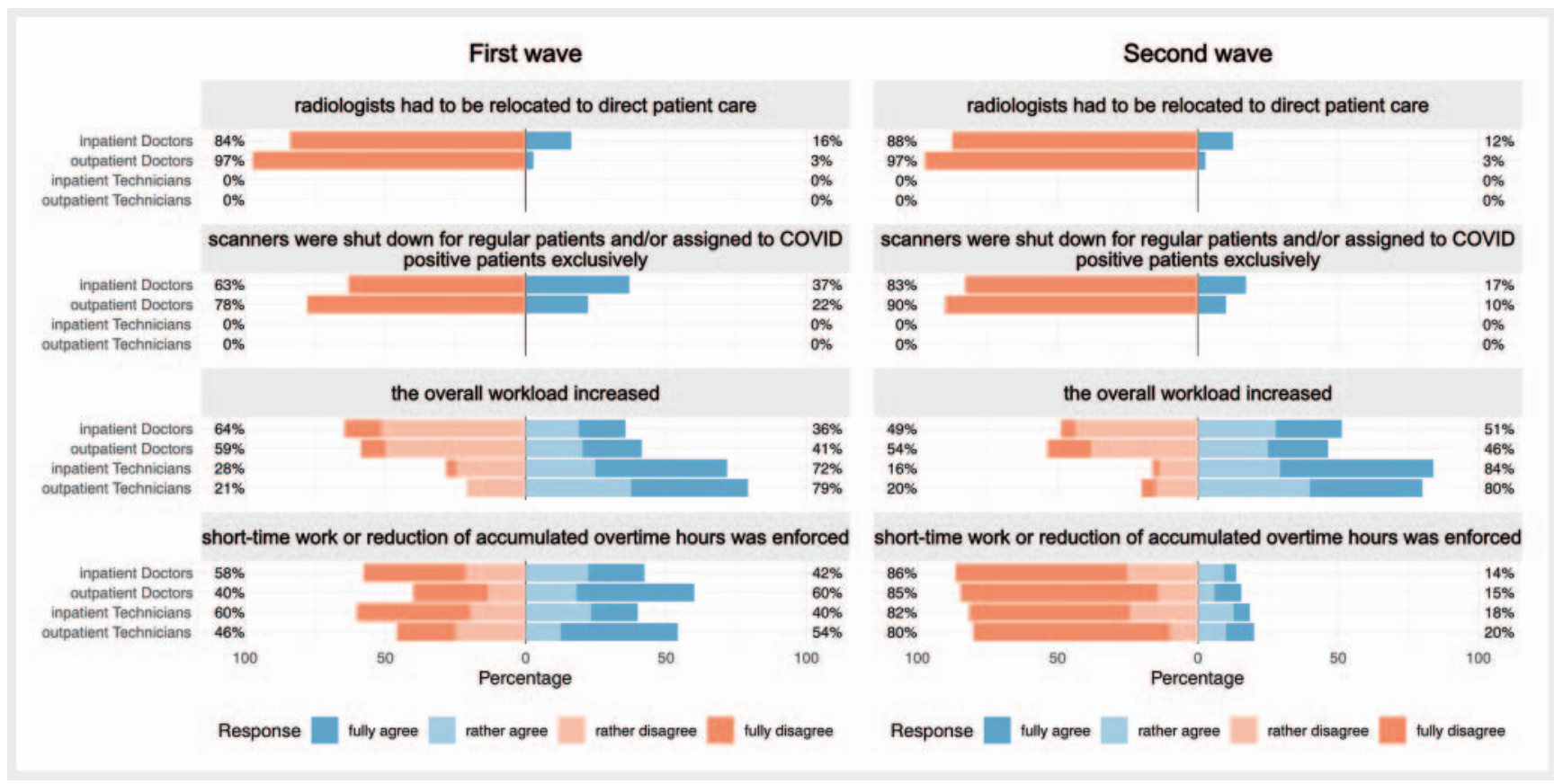

- Fig. 5 Responses to the direct consequences section: first vs. second wave. Total answers for each question, counted from the top: \#1 wave: 147, 165, 689, 691; \#2 wave: 141, 145, 621, 622. Questions 1, 2 were only part of the dedicated survey for head physicians.

- Abb. 5 Antworten zum Abschnitt „Direkte Konsequenzen“: erste vs. zweite Welle. Gesamtantworten für jede Frage, von oben gezählt: \#1 Welle: 147, 165, 689, 691; \#2 Welle: 141, 145, 621, 622. Die Fragen 1 und 2 waren nur Teil der spezifischen Umfrage für Chefärzt/innen.

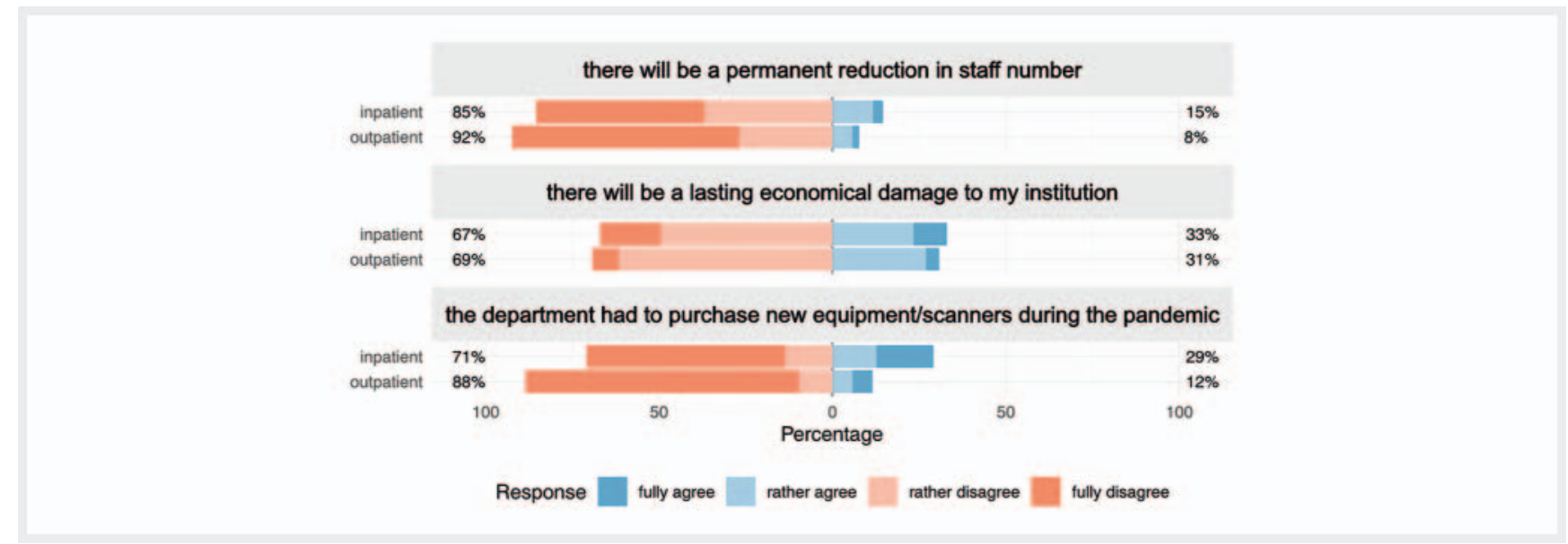

- Fig. 6 Responses to the long-term consequences section. The questions were only part of the dedicated survey for head physicians. Total answers for each question: 155 .

- Abb.6 Antworten zum Abschnitt „Langzeitfolgen“. Die Fragen waren nur Teil der spezifischen Umfrage für Chefärzt/innen. Gesamtantworten für jede Frage: 155.

\section{Perspectives}

Most participants disagreed that the COVID-19 pandemic will lead to a permanent reduction of the number of staff or lasting economic damage to their department ( $\triangleright$ Fig. 6 ).

\section{Discussion}

The COVID-19 pandemic is dynamically impacting radiology around the world with varying experiences and crisis strategies $[11,13,14,21]$. The results of our nationwide survey provide an analysis of the subjective impact of the COVID-19 pandemic on radiology in outpatient and inpatient care for radiologists and 
- Table 1 Approximation of equipment that was shut down in inpatient and outpatient care during the first and second wave.

\ Tab. 1 Schätzung der stillgelegten Geräte in der stationären und ambulanten Versorgung während der ersten und zweiten Welle.

\begin{tabular}{|c|c|c|c|c|c|c|c|}
\hline equipment & wave & $\begin{array}{l}\text { absolute } \\
\text { responses }\end{array}$ & mean & Std error & $\begin{array}{l}\text { lower } \\
95 \%\end{array}$ & $\begin{array}{l}\text { upper } \\
95 \%\end{array}$ & $\begin{array}{l}\mathrm{p}>|\mathrm{t}| \\
\text { (waves) }\end{array}$ \\
\hline \multicolumn{8}{|l|}{ inpatient } \\
\hline \multirow[t]{2}{*}{$\%$ CT } & $\# 1$ & 53 & 17.02 & 2.64 & 11.78 & 22.26 & 0.049 \\
\hline & $\# 2$ & 42 & 9.10 & 2.96 & 3.21 & 14.98 & \\
\hline \multirow[t]{2}{*}{$\% \mathrm{MRI}$} & $\# 1$ & 48 & 13.71 & 2.78 & 8.18 & 19.24 & 0.036 \\
\hline & $\# 2$ & 39 & 4.87 & 3.09 & -1.26 & 11.01 & \\
\hline \multirow[t]{2}{*}{$\%$ angiography } & $\# 1$ & 39 & 9.62 & 3.14 & 3.36 & 15.87 & 0.587 \\
\hline & $\# 2$ & 37 & 7.16 & 3.22 & 0.74 & 13.59 & \\
\hline \multirow[t]{2}{*}{ \% fluoroscopy } & $\# 1$ & 38 & 7.11 & 2.67 & 1.78 & 12.43 & 0.385 \\
\hline & $\# 2$ & 37 & 3.78 & 2.71 & -1.61 & 9.18 & \\
\hline \multirow[t]{2}{*}{ \% stat. X-ray } & $\# 1$ & 45 & 14.89 & 2.62 & 9.69 & 20.09 & 0.029 \\
\hline & \#2 & 43 & 6.58 & 2.68 & 1.26 & 11.91 & \\
\hline \multirow[t]{2}{*}{ \% mob. X-ray } & $\# 1$ & 45 & 14.24 & 2.82 & 8.63 & 19.86 & 0.123 \\
\hline & $\# 2$ & 40 & 7.95 & 2.99 & 1.99 & 13.91 & \\
\hline \multicolumn{8}{|l|}{ outpatient } \\
\hline \multirow[t]{2}{*}{$\%$ CT } & $\# 1$ & 16 & 23.88 & 6.25 & 11.03 & 36.73 & 0.021 \\
\hline & $\# 2$ & 12 & 0.42 & 7.22 & -14.42 & 15.25 & \\
\hline \multirow[t]{2}{*}{$\% \mathrm{MRI}$} & $\# 1$ & 16 & 16.38 & 4.69 & 6.79 & 25.97 & 0.052 \\
\hline & $\# 2$ & 15 & 2.73 & 4.84 & -7.17 & 12.64 & \\
\hline \multirow[t]{2}{*}{ \% angiography } & $\# 1$ & 2 & 0 & 0 & 0 & 0 & $\mathrm{~N} / \mathrm{A}$ \\
\hline & $\# 2$ & 0 & $\mathrm{n} / \mathrm{a}$ & $\mathrm{n} / \mathrm{a}$ & $\mathrm{n} / \mathrm{a}$ & $\mathrm{n} / \mathrm{a}$ & \\
\hline \multirow[t]{2}{*}{ \% fluoroscopy } & $\# 1$ & 4 & 50.00 & 30.62 & -35.01 & 135.01 & 1.000 \\
\hline & $\# 2$ & 2 & 50.00 & 43.30 & -70.22 & 170.22 & \\
\hline \multirow[t]{2}{*}{ \% stat. X-ray } & $\# 1$ & 15 & 18.40 & 5.20 & 7.67 & 29.13 & 0.040 \\
\hline & $\# 2$ & 11 & 1.00 & 6.07 & -11.53 & 13.54 & \\
\hline \multirow[t]{2}{*}{ \% mob. X-ray } & $\# 1$ & 3 & 16.67 & 16.67 & -55.00 & 88.38 & 0.667 \\
\hline & \#2 & 1 & 0 & 0 & 0 & 0 & \\
\hline
\end{tabular}

These questions were exclusively part of the dedicated survey for head physicians. Statistical analysis compared the results of the first wave with the second wave for each machine applying one-way Anova (mean, std error, lower/upper $95 \%$ ) and two-tailed Student's t-test (p-value). mob.: mobile; stat.: stationary. Diese Fragen waren ausschließlich Teil der spezifischen Umfrage für Chefärzt/innen. Für die statistische Analyse verglichen wir die Ergebnisse der ersten Welle mit der zweiten Welle für jedes Gerät mittels Oneway-Anova (Mittelwert, Standardfehler, untere/obere $95 \%$ ) und 2-seitigem Student's-t-Test (p-Wert). mob = mobil; stat = stationär.

technicians during the first and second wave in Germany. Major findings include that a substantial proportion of respondents were not satisfied with the communication, support, and financial aid provided by the government. In the second wave, fewer participants indicated a lack of personal protective equipment. Participants indicated that in the second wave, more examinations were conducted again. Since the number of delayed emergency examinations did not change significantly between the waves, elective, previously postponed examinations were most likely responsible for this increase [22]. It should be emphasized that almost threefourths of the technicians but only approximately $50 \%$ of doctors reported an increased workload. Infections and quarantine rates were higher in technicians than in radiologists.

Limited supplies of face masks was a generally known and ubiquitously discussed topic [23]. We therefore focused our analysis of lacking personal protective equipment on additionally needed equipment like disinfectant, gloves, or eye protection [24, 25]. Technicians work in close contact with patients with potential or proven COVID-19 infection and carry a high risk of infection [26]. This is in line with our findings that more technicians were infected or had to pursue quarantine measures compared to radiologists. Moreover, this might be one important factor leading to the feeling 
- Table 2 Approximation of decrease in examinations for the respective scanners in inpatient and outpatient care during the first and second wave.

- Tab.2 Schätzung der Reduktion der Untersuchungen für die jeweiligen Scanner in der stationären und ambulanten Versorgung während der ersten und zweiten Welle.

\begin{tabular}{|c|c|c|c|c|c|c|c|}
\hline equipment & wave & $\begin{array}{l}\text { absolute } \\
\text { responses }\end{array}$ & mean & Std error & $\begin{array}{l}\text { lower } \\
95 \%\end{array}$ & $\begin{array}{l}\text { upper } \\
95 \%\end{array}$ & $\begin{array}{l}p>|t| \\
\text { (waves) }\end{array}$ \\
\hline \multicolumn{8}{|l|}{ inpatient } \\
\hline \multirow[t]{2}{*}{$\%$ CT } & $\# 1$ & 79 & 18.59 & 1.76 & 15.12 & 22.07 & 0.003 \\
\hline & $\# 2$ & 57 & 10.35 & 2.07 & 6.26 & 14.45 & \\
\hline \multirow[t]{2}{*}{$\% \mathrm{MRI}$} & $\# 1$ & 74 & 23.47 & 2.01 & 19.50 & 27.45 & 0.003 \\
\hline & $\# 2$ & 56 & 14.29 & 2.31 & 9.72 & 18.85 & \\
\hline \multirow[t]{2}{*}{$\%$ angiography } & $\# 1$ & 62 & 21.77 & 2.74 & 16.35 & 27.20 & 0.119 \\
\hline & $\# 2$ & 49 & 15.31 & 3.08 & 9.20 & 21.41 & \\
\hline \multirow[t]{2}{*}{ \% fluoroscopy } & $\# 1$ & 59 & 19.24 & 2.70 & 13.89 & 24.58 & 0.028 \\
\hline & $\# 2$ & 47 & 10.21 & 3.02 & 4.22 & 16.20 & \\
\hline \multirow[t]{2}{*}{ \% stat. X-ray } & $\# 1$ & 68 & 17.72 & 1.85 & 14.07 & 21.37 & 0.002 \\
\hline & $\# 2$ & 52 & 8.750 & 2.11 & 4.57 & 12.93 & \\
\hline \multirow[t]{2}{*}{ \% mob. X-ray } & $\# 1$ & 55 & 10.64 & 2.12 & 6.42 & 14.85 & 0.212 \\
\hline & $\# 2$ & 47 & 6.70 & 2.30 & 2.14 & 11.26 & \\
\hline \multicolumn{8}{|l|}{ outpatient } \\
\hline \multirow[t]{2}{*}{$\% \mathrm{CT}$} & $\# 1$ & 25 & 31.40 & 3.72 & 23.90 & 38.90 & $<0.001$ \\
\hline & $\# 2$ & 20 & 8.75 & 4.16 & 0.36 & 17.14 & \\
\hline \multirow[t]{2}{*}{$\% \mathrm{MRI}$} & $\# 1$ & 24 & 24.67 & 3.33 & 17.95 & 31.39 & 0.004 \\
\hline & $\# 2$ & 21 & 9.81 & 3.56 & 2.63 & 16.99 & \\
\hline \multirow[t]{2}{*}{$\%$ angiography } & $\# 1$ & 3 & 23.33 & 14.53 & -39.18 & 85.85 & 0.919 \\
\hline & $\# 2$ & 1 & 20.00 & 25.17 & -88.28 & 128.28 & \\
\hline \multirow[t]{2}{*}{ \% fluoroscopy } & $\# 1$ & 7 & 50.00 & 13.96 & 18.42 & 81.58 & 0.194 \\
\hline & $\# 2$ & 4 & 17.50 & 18.47 & -24.27 & 59.27 & \\
\hline \multirow[t]{2}{*}{ \% stat. X-ray } & $\# 1$ & 21 & 26.67 & 3.87 & 18.83 & 34.50 & 0.013 \\
\hline & $\# 2$ & 18 & 11.78 & 4.18 & 3.31 & 20.24 & \\
\hline \multirow[t]{2}{*}{ \% mob. X-ray } & $\# 1$ & 5 & 28.00 & 7.63 & 9.33 & 46.67 & 0.138 \\
\hline & $\# 2$ & 3 & 6.67 & 9.85 & -17.44 & 30.77 & \\
\hline
\end{tabular}

These questions were exclusively part of the dedicated survey for head physicians. Statistical analysis compared the results of the first wave with the second wave for each machine applying one-way Anova (mean, std error, lower/upper $95 \%$ ) and two-tailed Student's t test (p-value). mob.: mobile; stat.: stationary. Diese Fragen waren ausschließlich Teil der spezifischen Befragung für Chefärzt/innen. Für die statistische Analyse verglichen wir die Ergebnisse der ersten Welle mit der zweiten Welle für jedes Gerät mittels Oneway-Anova (Mittelwert, Standardfehler, untere/obere 95\%) und 2-seitigem Student's-t-Test (p-Wert). mob = mobil; stat = stationär.

of increased workload among technicians which was also pronounced during the second wave. The healthcare system has to face this important issue to guarantee the health and working force of technicians who are essential players in the current pandemic [26]. Our study has limitations that warrant discussion. With $\mathrm{n}=441 \mathrm{ID}$ and $\mathrm{n}=271 \mathrm{ITs}$, we might have been able to draw a quite solid subjective impression of the inpatient sector whereas the results of the outpatient sector ( $n=143, O D ; n=26$, OT) may have an increased bias and should not be overstated. Especially the OT subgroup might have a selection bias. We did not perform a pilot test prior to the nationwide survey distribution because of the urgency of the current pandemic crisis. An influence of lacking psychometric assessment cannot be ruled out. We conducted a nationwide survey across outpatient and inpatient care, and regional differences of COVID-19 infectious spread may have led to distortions in the assessment. The dedicated analysis of regional differences was beyond the scope of the current manuscript which aimed to achieve a nationwide analysis. The anonymous survey was freely available online and distributed via a multitude of mailing lists. It cannot be ruled out that some respondents participated repeatedly or that 
- Table 3 Approximation of delayed emergency examinations for the respective scanners in inpatient and outpatient care during the first and second wave.

- Tab.3 Schätzung verzögerter Notfalluntersuchungen für die jeweiligen Scanner in der stationären und ambulanten Versorgung während der ersten und zweiten Welle.

\begin{tabular}{|c|c|c|c|c|c|c|c|}
\hline equipment & wave & $\begin{array}{l}\text { absolute } \\
\text { responses }\end{array}$ & mean & Std error & $\begin{array}{l}\text { lower } \\
95 \%\end{array}$ & $\begin{array}{l}\text { upper } \\
95 \%\end{array}$ & $\begin{array}{l}p>|t| \\
\text { (waves) }\end{array}$ \\
\hline \multicolumn{8}{|l|}{ inpatient } \\
\hline \multirow[t]{2}{*}{$\% \mathrm{CT}$} & \#1 & 57 & 2.37 & 0.74 & 0.89 & 3.84 & 0.427 \\
\hline & \#2 & 50 & 1.50 & 0.79 & -0.08 & 3.08 & \\
\hline \multirow[t]{2}{*}{$\% \mathrm{MRI}$} & $\# 1$ & 52 & 1.92 & 0.74 & 0.45 & 3.39 & 0.162 \\
\hline & \#2 & 48 & 0.42 & 0.77 & -1.11 & 1.95 & \\
\hline \multirow[t]{2}{*}{ \% angiography } & $\# 1$ & 46 & 4.57 & 1.37 & 1.83 & 7.30 & 0.149 \\
\hline & \#2 & 42 & 1.67 & 1.44 & -1.19 & 4.53 & \\
\hline \multirow[t]{2}{*}{ \% fluoroscopy } & \#1 & 46 & 1.30 & 0.65 & 0.004 & 2.60 & 0.375 \\
\hline & \#2 & 43 & 0.47 & 0.68 & -0.88 & 1.81 & \\
\hline \multirow[t]{2}{*}{ \% stat. X-ray } & $\# 1$ & 51 & 0.88 & 0.50 & -0.11 & 1.87 & 0.917 \\
\hline & \#2 & 47 & 0.96 & 0.52 & -0.07 & 1.99 & \\
\hline \multirow[t]{2}{*}{ \% mob. X-ray } & $\# 1$ & 49 & 0.92 & 0.49 & -0.06 & 1.90 & 0.864 \\
\hline & \#2 & 44 & 0.80 & 0.52 & -0.24 & 1.83 & \\
\hline \multicolumn{8}{|l|}{ outpatient } \\
\hline \multirow[t]{2}{*}{$\%$ CT } & $\# 1$ & 17 & 4.24 & 1.34 & 1.51 & 6.96 & 0.228 \\
\hline & \#2 & 16 & 1.88 & 1.38 & -0.94 & 4.69 & \\
\hline \multirow[t]{2}{*}{$\% \mathrm{MRI}$} & $\# 1$ & 13 & 4.62 & 1.85 & 0.81 & 8.42 & 0.344 \\
\hline & \#2 & 14 & 2.14 & 1.78 & -1.52 & 5.81 & \\
\hline \multirow[t]{2}{*}{$\%$ angiography } & \#1 & 2 & 0 & 0 & 0 & 0 & $\mathrm{~N} / \mathrm{A}$ \\
\hline & $\# 2$ & 1 & 0 & 0 & 0 & 0 & \\
\hline \multirow[t]{2}{*}{ \% fluoroscopy } & $\# 1$ & 3 & 0 & 0 & 0 & 0 & $\mathrm{~N} / \mathrm{A}$ \\
\hline & \#2 & 3 & 0 & 0 & 0 & 0 & \\
\hline \multirow[t]{2}{*}{ \% stat. X-ray } & $\# 1$ & 12 & 5.42 & 2.33 & 0.60 & 10.24 & 0.125 \\
\hline & \#2 & 12 & 0.17 & 2.33 & -4.65 & 4.99 & \\
\hline \multirow[t]{2}{*}{ \% mob. X-ray } & $\# 1$ & 2 & 0 & 0 & 0 & 0 & $\mathrm{~N} / \mathrm{A}$ \\
\hline & \#2 & 2 & 0 & 0 & 0 & 0 & \\
\hline
\end{tabular}

These questions were exclusively part of the dedicated survey for head physicians. Statistical analysis compared the results of the first wave with the second wave for each machine applying one-way Anova (mean, std error, lower/upper $95 \%$ ) and two-tailed Student's t test (p-value). DEE: delayed emergency examinations; mob.: mobile; stat.: stationary.

Diese Fragen waren ausschließlich Teil der spezifischen Befragung für Chefärzt/innen. Für die statistische Analyse verglichen wir die Ergebnisse der ersten Welle mit der zweiten Welle für jedes Gerät mittels Oneway-Anova (Mittelwert, Standardfehler, untere/obere 95 \%) und 2-seitigem Student's-t-Test (p-Wert). DEE = verzögerte Notfalluntersuchungen; $m o b=$ mobil; stat = stationär.

people other than radiologists or technicians participated. The survey was voluntary which might impose a selection bias. The current survey gives an impression of this rapidly evolving pandemic at the end of the second wave. To increase the accuracy regarding the overall effects on radiology, we will conduct a follow-up survey during and beyond the crisis especially elucidating the impact of COVID-19 vaccines [27].

\section{Conclusion}

In conclusion, our nationwide survey provides an analysis of the subjective impressions of radiologists and technicians concerning the impact of the COVID-19 pandemic on outpatient and inpatient radiology in Germany. Although we could show that the majority of measures were felt to have improved from the first to the second wave, we have to note that an increasing number of technicians feel that they have an increased workload. Moreover, most 
- Table 4 Approximation of personnel with infection or quarantine isolation in inpatient and outpatient care during the first and second wave.

\ Tab.4 Schätzung des infizierten oder quarantänepflichtigen Personals in der stationären und ambulanten Versorgung während der ersten und zweiten Welle.

\begin{tabular}{|c|c|c|c|c|c|c|c|}
\hline personnel & wave & number & mean & Std error & $\begin{array}{l}\text { lower } \\
95 \%\end{array}$ & $\begin{array}{l}\text { upper } \\
95 \%\end{array}$ & $\begin{array}{l}p>|t| \\
\text { (waves) }\end{array}$ \\
\hline \multicolumn{8}{|l|}{ inpatient } \\
\hline \multirow[t]{2}{*}{$\%$ inf. radiologist } & $\# 1$ & 100 & 1.92 & 0.53 & 0.88 & 2.96 & 0.290 \\
\hline & $\# 2$ & 88 & 2.74 & 0.56 & 1.63 & 3.85 & \\
\hline \multirow[t]{2}{*}{ \% inf. technician } & $\# 1$ & 100 & 2.97 & 0.59 & 1.80 & 4.14 & 0.174 \\
\hline & $\# 2$ & 89 & 4.15 & 0.63 & 2.91 & 5.38 & \\
\hline \multirow[t]{2}{*}{$\%$ quar. radiologist } & $\# 1$ & 101 & 4.32 & 0.75 & 2.83 & 5.80 & 0.328 \\
\hline & $\# 2$ & 87 & 5.40 & 0.81 & 3.80 & 7.00 & \\
\hline \multirow[t]{2}{*}{ \% quar. technician } & $\# 1$ & 101 & 8.42 & 0.97 & 6.49 & 10.32 & 0.947 \\
\hline & $\# 2$ & 87 & 8.31 & 1.05 & 6.25 & 10.37 & \\
\hline \multicolumn{8}{|l|}{ outpatient } \\
\hline \multirow[t]{2}{*}{$\%$ inf. radiologist } & $\# 1$ & 54 & 1.87 & 1.83 & -1.76 & 5.50 & 0.400 \\
\hline & $\# 2$ & 39 & 4.26 & 2.15 & -0.01 & 8.53 & \\
\hline \multirow[t]{2}{*}{ \% inf. technician } & $\# 1$ & 56 & 2.89 & 1.85 & -0.77 & 6.56 & 0.442 \\
\hline & $\# 2$ & 40 & 5.10 & 2.18 & 0.77 & 9.44 & \\
\hline \multirow[t]{2}{*}{ \% quar. radiologist } & $\# 1$ & 47 & 3.34 & 1.60 & 0.17 & 6.51 & 0.510 \\
\hline & $\# 2$ & 38 & 4.92 & 1.77 & 1.39 & 8.45 & \\
\hline \multirow[t]{2}{*}{ \% quar. technician } & $\# 1$ & 51 & 7.88 & 1.95 & 4.02 & 11.75 & 0.854 \\
\hline & $\# 2$ & 44 & 8.41 & 2.10 & 4.25 & 12.57 & \\
\hline
\end{tabular}

These questions were exclusively part of the dedicated survey for head physicians. Statistical analysis compared the results of the first wave with the second wave for each machine applying one-way Anova (mean, std error, lower/upper $95 \%$ ) and two-tailed Student's t test (p-value). inf.: infected; quar.: in quarantine.

Diese Fragen waren ausschließlich Teil der spezifischen Befragung für Chefärzt/innen. Für die statistische Analyse verglichen wir die Ergebnisse der ersten Welle mit der zweiten Welle für jedes Gerät mittels Oneway-Anova (Mittelwert, Standardfehler, untere/obere $95 \%$ ) und 2-seitigem Student's-t-Test ( $p$-Wert). inf = infiziert; quar = in Quarantäne.

respondents state that the financial support from the government could be improved. In particular, the measures that did not show a trend of improvement from the first to the second wave based on the participants' responses should be tackled to ensure efficient healthcare structures.

$\begin{array}{ll}\text { ABBREVIATIONS } \\ \text { COVID-19 } & \text { Coronavirus disease } 2019 \\ \text { IC } & \text { inpatient care } \\ \text { ID } & \text { inpatient doctor } \\ \text { IT } & \text { inpatient technician } \\ \text { OC } & \text { outpatient care } \\ \text { OD } & \text { outpatient doctor } \\ \text { OT } & \text { outpatient technician } \\ \text { RT-PCR } & \text { real-time polymerase chain reaction } \\ \text { WHO } & \text { World Health Organization }\end{array}$

\section{Declarations}

\section{Ethics approval and consent to participate}

This anonymous survey was exempt from approval by the institutional review board.

\section{Availability of data and materials}

The datasets used and/or analyzed during the current study are available from the corresponding author upon reasonable request.

\section{Funding}

The study was funded in part by the German Federal Ministry of Education and Research (BMBF) as part of the University Medicine Network. The funding body did not influence the design of the study, the collection, analysis, and interpretation of data, or the writing of the manuscript. 


\section{Authors' contributions}

SB contributed substantially to the conception and design of the study and to the acquisition, analysis, and interpretation of the data and drafted the paper. SA contributed substantially to the conception and design of the study and to the acquisition, analysis, and interpretation of the data and substantively revised the paper. AO contributed substantially to the conception and design of the study and to the acquisition of data. KN contributed substantially to the conception and design of the study and to the acquisition of data and substantively revised the paper. MMS contributed substantially to the conception and design of the study and to the acquisition of data. MJS contributed substantially to the conception and design of the study and to the acquisition of the data. DPdS contributed substantially to the conception and design of the study and to the acquisition, analysis, and interpretation of the data and substantively revised the work. TP contributed substantially to the conception and design of the study and to the acquisition of data. AMB contributed substantially to the conception and design of the study and to the acquisition of data. BH contributed substantially to the conception and design of the study and to the acquisition of data. TJV contributed substantially to the conception and design of the study and to the acquisition, analysis, and interpretation of the data and substantively revised the paper. BB contributed substantially to the conception and design of the study and to the acquisition, analysis, and interpretation of the data and substantively revised the paper. All authors read and approved the final manuscript. All authors have agreed to be personally accountable for the author's own contributions and to ensure that questions related to the accuracy or integrity of any part of the study, even ones in which the author was not personally involved, are appropriately investigated and resolved, and the resolution is documented in the literature.

\section{Conflict of Interest}

The authors declare that they have no conflict of interest.

\section{References}

[1] World Health Organization. COVID-19 Weekly Epidemiological Update. World Heal Organ. 2021: 1-25

[2] Dong E, Du H, Gardner L. An interactive web-based dashboard to track COVID-19 in real time. Lancet Infect Dis 2020; 20: 533-534

[3] COVID-19 Dashboard by the Center for Systems Science and Engineering (CSSE) at Johns Hopkins University; JHU CSSE COVID-19 Data. https://github.com/CSSEGISandData/COVID-19; accessed 29th june 2021

[4] Kanne JP, Little BP, Chung JH et al. Essentials for radiologists on COVID-19: An update-radiology scientific expert panel. Radiology 2020; 296: E113E114

[5] Fang Y, Zhang H, Xie J et al. Senivity of Chest CT for COVID.19: Comparasion to RT-PCR. Radiology 2020; 296: E115-E117

[6] Ai T, Yang Z, Hou $\mathrm{H}$ et al. Correlation of Chest CT and RT-PCR Testing for Coronavirus Disease 2019 (COVID-19) in China: A Report of 1014 Cases. Radiology 2020; 296: E32-E40

[7] Bernheim A, Mei X, Huang $M$ et al. Chest $C T$ findings of coronavirus disease 2019 (COVID-19). Radiology 2020; 295: 685-691
[8] Feldt T, Guggemos W, Heim K et al. Hinweise zu Erkennung, Diagnostik und Therapie von Patienten mit COVID-19. Ständiger Arbeitskr. Der Kompetenz- Und Behandlungszentren Für Krankheiten Durch Hochpathogene Erreger Am Robert-Koch-Institut. 2021: 1-25

[9] Chandy PE, Umer Nasir M, Srinivasan S et al. Interventional radiology and COVID-19: evidence-based measures to limit transmission. Diagnostic Interv Radiol 2020; 26: 236-240

[10] Akyurt N. Knowledge, practice and emotional status related to COVID-19 pandemic among radiology technicians working at pandemic hospitals. Eur J Radiol 2020; 134: 109431

[11] Mossa-Basha M, Schnall M, Meltzer C et al. Special Report of the RSNA COVID-19 Task Force: Crisis Leadership of Major Health System Radiology Departments During COVID-19. Radiology 2021; 299: E187-E192

[12] Dizdarevic S, Abdulla M, Sewedy T et al. Impact of COVID-19 on nuclear medicine in the UK. Nucl Med Commun 2021; 42: 138-149

[13] Cavallo J], Forman HP. The economic impact of the COVID-19 pandemic on radiology practices. Radiology 2020; 296: E141-E144

[14] Sharpe RE, Kuszyk BS, Mossa-Basha M. Special Report of the RSNA COVID-19 Task Force: The Short- and Long-term Financial Impact of the COVID-19 Pandemic on Private Radiology Practices. Radiology 2021; 298: E11-E18

[15] Larocque N, Shenoy-Bhangle A, Brook A et al. Resident Experiences With Virtual Radiology Learning During the COVID-19 Pandemic. Acad Radiol 2021; 28: 704-710

[16] Alhasan AS, Alahmadi SM, Altayeb YA et al. Impact of COVID-19 Pandemic on Training and Well-Being in Radiology Residency: A National Survey of Diagnostic Radiology Trainees in Saudi Arabia. Acad Radiol 2021; 28: 1002-1009

[17] R Core Team (2021). R: A language and environment for statistical computing. Vienna, Austria: R Foundation for Statistical Computing. http://www.R-project.org/

[18] RStudio Team (2020). RStudio: Integrated Development for R. RStudio, PBC, Boston, MA. http://www.rstudio.com/

[19] Bundesärztekammer, Statisitk der BÄK SB. Ärztestatistik zum 31. Dezember 2019. 2019

[20] Müller-Rawlins E. Fachkräftemangel MTA; Januar 2019. Stat. Bundesagentur Für Arbeit, Branchenmonitoring, Rheinland-Pfalz 2017, Minist. Für Soziales, Arbeit, Gesundh. Und Demogr. DVA, Dachverband Für Technol. Und Anal. Der Medizin Deutschl. e. V. n. d.

[21] Tan BP, Lim KC, Goh YG et al. Radiology Preparedness in the Ongoing Battle against COVID-19: Experiences from Large to Small Public Hospitals in Singapore. Radiol Cardiothorac Imaging 2020; 2: e200140

[22] Boettcher AN, Hammoud DA, Weinberg JB et al. Cancer Imaging and Patient Care during the COVID-19 Pandemic. Radiol Imaging Cancer 2020; 2: e200058

[23] Feng S, Shen C, Xia N et al. Rational use of face masks in the COVID-19 pandemic. Lancet Respir Med 2020; 8: 434-436

[24] Guo ZD, Wang ZY, Zhang SF et al. Aerosol and Surface Distribution of Severe Acute Respiratory Syndrome Coronavirus 2 in Hospital Wards, Wuhan, China, 2020. Indoor Built Environ 2020; 26: 1586-1591

[25] Chu DK, Akl EA, Duda $S$ et al. Physical distancing, face masks, and eye protection to prevent person-to-person transmission of SARS-CoV-2 and COVID-19: a systematic review and meta-analysis. Lancet 2020; 395: 1973-1987

[26] Zhao Y, Xiang C, Wang $S$ et al. Radiology department strategies to protect radiologic technologists against COVID19: Experience from Wuhan. Eur J Radiol J 2020; 127: 108996

[27] Wouters OJ, Shadlen KC, Salcher-Konrad M et al. Challenges in ensuring global access to COVID-19 vaccines: production, affordability, allocation, and deployment. Lancet 2021; 6736: 1-12 